\title{
Characterisation of geomaterials and non-conventional waste streams for their reuse as engineered materials
}

\author{
Claudio Oggeri ${ }^{1}$, and Raffaele Vinai ${ }^{2, *}$ \\ ${ }^{1}$ Politecnico di Torino, DIATI, Corso Duca degli Abruzzi 24, 10129 Turin, Italy \\ ${ }^{2}$ University of Exeter, CEMPS, Harrison Building, North Park Road, Exeter EX4 4QF, United Kingdom
}

\begin{abstract}
Reusing bulk volumes of waste material is a requirement often encountered in mining and construction activities involving excavations. Spoils produced from these activities typically show high variability in terms of properties and behaviour, due to the local geology, adopted excavation method and further spoil treatments. A procedure for classifying the spoil from tunnelling was proposed in order to correlate ground type, possible muck destination and treatment type. With a similar approach in industrial and related sectors, the reuse of non-conventional materials (i.e. wooden chips, fragments, granulates, micronized glass, residual out of shape from manufacturing processes or coming from selection of other waste) has a great relevance as it is accompanied by savings in disposal costs and in the sourcing of raw materials. Characterisation tests derived from geotechnical engineering can support the assessment of the physical and mechanical properties of non-conventional materials, creating a feedback loop encompassing raw material description, required treatments, and possible utilisations as engineered materials. This paper describes the possible screening tests and treatment options for material recycling in the framework of a modified spoil classification system.
\end{abstract}

\section{Background}

The reuse and recycling of waste material from excavation and mining/quarrying activities is a global issue that received significant attention in the last decades. The quantification of the volume of excavated rock and soil materials is not a straightforward task, as this figure is often included into construction and demolition waste (C\&DW) in official statistics and further details are not always available. In Europe, C\&DW represents about $30 \%$ of the total generated waste, accounting for more than 850 million tonnes per year [1]. A recent statistics from the UK Department for Environment, Food \& Rural Affairs (DEFRA) concluded that soils represented more than $26 \%$ of the total waste produced in 2016 and about $43 \%$ of C\&DW [2]. It is therefore possible to estimate that more than 400 million tonnes of waste soils are produced yearly in EU. In addition, about 634 million tonnes of waste are produced from mining and quarrying activities according to EU official statistics Eurostat, suggesting that the production of geomaterial waste in EU exceeds one billion tonnes per year.

Whilst the success of effective reuse and recycle of waste geomaterials has to be planned since the preliminary stage of any infrastructure project [3], the high variability of the physical and chemical nature of excavation waste adds a significant uncertainty to such planning [4]. The environmental compatibility of excavated materials needs to be ascertained even before assessing the physical and mechanical properties of the spoil materials [5], and thus bringing a further degree of complexity in the recycling activities, particularly in the case of materials potentially contaminated by excavation techniques [6].

Despite these difficulties, the benefits from waste geomaterial reuse and recycle are huge and fully recognised in the technical literature [7]; in specific conditions they can lead to significant environmental savings, e.g. a reduction of more than $35 \%$ of greenhouse gasses emissions related to soil and rock transportation [8]. Notably, geotechnical works required for transportation infrastructure projects are resourceintensive activities that have high potential for the reuse and recycle of excavation geomaterials [9].

Modern literature points out the importance of a material flow approach for managing the use of excavation waste soils and rocks (e.g. $[10,11])$. Overall, the links among local geology, excavation methods, spoil treatment and strategies for recycle within the project have been identified in the literature [12], stressing the importance of early physical, chemical and mechanical characterisation of spoils, well ahead the start of the excavation works.

The emergence of a range of industrial waste streams and the environmental, economic and technical considerations arising from their recycle and reuse still need a comprehensive discussion. The experience learnt from the development of suitable methodologies for characterisation and management of waste geomaterial

*Corresponding author: r.vinai@exeter.ac.uk 
can be extended to other waste such as glass waste, granulates, chipping particles and the likes, which show similarities with soils and geomaterials in terms of 'bulk behaviour'.

This paper describes criteria for identifying muck recovery strategies developed by the Authors, and then proposes a possible extension of such methodology to non-conventional bulk waste streams, assessing potentials and limitations of this exercise.

\section{Classification method for tunnel spoil}

Tunnels and underground structures indubitably play a fundamental role in infrastructures for modern society, providing transportation, water access and sewage management facilities in urban environment as well as across mountain regions. Worldwide, tunnelling produces billions of tonnes of excavated material that, when not reused, becomes a waste product that must be managed [3].

\subsection{Management of excavated muck}

The management of excavation spoils has been discussed in the literature, with emphasis on the flow of the material from excavation to reuse/disposal of the spoils [4]. A multi-criteria methodology needs to take into account parameters that have mutual influence: geological conditions, excavation techniques, in-situ treatment of spoil, and final destination of the material [13].

\subsubsection{Geological conditions}

Tunnels excavation can be carried out in a wide range of natural occurring materials, from hard rock to weak, organic soils, and most of the time the nature of the geology varies over the tunnelling drive. Alluvial deposits can show variability due to the deposition history of the site, whereas rock mass formations can show variability due to strata variations, alterations or weathering. If the site geology involves special mineralogical occurrences (e.g. asbestos, quartzite, radioactive minerals), or contaminations (from industrial or commercial activities, or decommissioned landfilling), particular care is needed in assessing the environmental compatibility of materials for reuse; in most of those cases, the recycle is not feasible nor viable, and disposal options need to be addressed.

\subsubsection{Excavation techniques}

The choice of adopted excavation method is typically influenced by local geology, length of the excavation, specific site conditions or economic and contractual considerations. Broadly speaking, excavation methods can be divided in four categories: (i) drill and blast, (ii) step-excavation with mechanical means, (iii) full face mechanical excavation, and (iv) special preliminary soil treatments and/or soil conditioning such as consolidation or foam injection. The excavation method influences the grain size distribution and grading of the muck, as well as the need for in-situ treatment and the need for environmental compatibility assessment.

\subsubsection{In-situ treatments of spoils}

Typical technical operations that are carried out on site for the improvement of the waste geomaterials are washing, sieving and sorting, desiccation, dewatering, crushing, lime or cement stabilisation, and compaction. For other ancillary phases, such as the grain size or grain shape control, or mineral separation, a specific treatment plant needs to be installed. The extent and complexity of in-situ treatment plant depend on the size of the project and the foreseen volume of excavated materials, the requirements for their final destination, economic considerations on local raw materials market, disposal options, local regulations and incentives for recycling.

\subsubsection{Final destination of the materials}

Common reuse strategies vary according to the quality of the spoils. A possible hierarchic ranking (from the highest to the lowest added value) of the different recovering options is as follows: (i) as aggregates or raw material for industrial production when the muck is of good quality or shows ore-related interest; (ii) as material for embankments, protection works or road construction when the muck is of fair quality; and (iii) as refilling material for voids or land reclamation when muck is of low quality.

According to the final destination of the material, specific characterisation tests need to be carried out for ensuring the suitability of reclaimed geomaterial, according to technical standards and environmental constraints. Obviously, the higher the added-value preidentified strategy for the reuse, the higher the quality required, and the stricter the characterisation campaign needs to be. Typical tests relate to the assessment of physical state (size, shape, specific gravity, roughness, void ratio, porosity) and mechanical properties (compressive strength and resistance to impact, fragmentation and crushing), as well as durability features (resistance to polishing, abrasion and wear, chemical composition and presence of hazardous substances, volumetric stability, water absorption and solubility, durability to frost and alkali-aggregate reaction for concrete preparation).

The possible end-use strategy mainly depends on the geological nature of the site, the adopted excavation method and the site treatment of the spoils.

\subsubsection{Environmental aspects}

The reuse of excavated materials is subjected to some restrictions following environmental compatibility considerations, and therefore chemical analyses are required for a proper classification of the geomaterial and its consequent use. As contaminants and pollutants can diffuse both in ground and in the water (in the form of leachate), a comparative analysis on both natural and 
reclaimed materials is highly recommended for assessing the concentration of contaminants according to applicable environmental regulations. Additives used during excavation generally possess biodegradation properties, which are mainly due to contact time, oxidation reactions, bacterial actions and soil remoulding, washing or desiccating processes. Concentration of marker substances needs to be monitored over a certain time, ensuring that its desired reduction below the mandatory threshold limits is fully achieved. Full face mechanical excavation often uses additives for soil conditioning purposes (surfactants, polymers, bentonite slurry, tail sealing greases, antiabrasion chemicals) that show different behaviours. While surfactants degrade in a relatively quick time (2-4 months), polymers and greases (these latter can only partially degrade) have a less straightforward behaviour, which can ultimately lead to high concentration of contaminants. Mortars and bentonite are not affected by biodegradation processes, instead these can produce leachates. Spoils stabilisation with lime addition typically increases the $\mathrm{pH}$ value due to alkalinity of $\mathrm{CaO}$. This could affect soil properties and therefore needs to be considered during early stage of planning.

\subsection{Proposed classification method}

A multi-criteria method that considers the parameters mentioned above and suggests possible reuse/recycle strategies has been developed by the Authors [3, 13]. The method identifies a range of 17 muck types (acronym MT) according to the combination of ground type and excavation method, also considering the interference of groundwater if present, see Tables 1 and 2.

Table 1. Muck type allocation, from [3], modified.

\begin{tabular}{|c|c|c|c|c|}
\hline Ground & \multirow{2}{*}{ Rock } & \multirow{2}{*}{$\begin{array}{l}\text { Soft } \\
\text { rock / } \\
\text { hard } \\
\text { soil }\end{array}$} & \multicolumn{2}{|c|}{ Soil } \\
\hline Technique & & & $\begin{array}{c}\text { Coarse } \\
\text { (granular) }\end{array}$ & $\begin{array}{c}\text { Fine } \\
\text { (cohesive) }\end{array}$ \\
\hline $\begin{array}{c}\text { Drill and } \\
\text { Blast (D\&B) }\end{array}$ & MT1 & MT2 & not applied & not applied \\
\hline $\begin{array}{l}\text { Mechanised } \\
\text { step } \\
\text { excavation } \\
\text { (n.a. in } \\
\text { presence of } \\
\text { water) }\end{array}$ & MT3 & MT4 & MT5 & MT6 \\
\hline $\begin{array}{l}\text { Mechanised } \\
\text { excavation } \\
\text { Full face }\end{array}$ & MT7 & MT8 & MT9 & MT10 \\
\hline $\begin{array}{l}\text { Mechanised } \\
\text { excavation } \\
\text { and soil } \\
\text { conditioning }\end{array}$ & $\begin{array}{c}\text { not } \\
\text { applied }\end{array}$ & MT11 & MT12 & MT13 \\
\hline $\begin{array}{l}\text { Grouting or } \\
\text { reinforcing } \\
\text { of the ground } \\
\text { in the above } \\
\text { techniques }\end{array}$ & MT14 & MT15 & MT16 & MT17 \\
\hline
\end{tabular}

According to the muck type, potential recycling options are depending with possible treatments for achieving required material quality.

Table 2. Muck type description, from [3], modified. Comments in italic refer to the presence of water.

\begin{tabular}{|c|c|}
\hline $\begin{array}{c}\text { Muck } \\
\text { type }\end{array}$ & Description \\
\hline MT1 & $\begin{array}{l}\text { Coarse to blocky fragments, angular shaped, } \\
\text { presence of fines due to over-comminution, Good } \\
\text { draining. Sometimes abrasivity issues. }{ }^{*} N o \\
\text { meaningful interference. }\end{array}$ \\
\hline MT2 & $\begin{array}{l}\text { Wide grain size distribution, tabular elements, } \\
\text { petrography variety, drainage could be a concern } \\
\text { also for hauling. *Muddy behaviour, adhesion issues }\end{array}$ \\
\hline MT3 & $\begin{array}{l}\text { Generally wide grain distribution in coarse fraction, } \\
\text { angular shape, sometimes abrasivity issues, }\end{array}$ \\
\hline MT4 & $\begin{array}{l}\text { Heterogeneous shaped and wide grain sizes, } \\
\text { heterogeneous mineralogy and consistency, bulking } \\
\text { attitude. }\end{array}$ \\
\hline MT5 & $\begin{array}{l}\text { Natural grain size distribution, rounded shaped } \\
\text { elements, possibly cobbles and boulders, abrasivity. }\end{array}$ \\
\hline MT6 & $\begin{array}{l}\text { Medium to fine grain size, easy to handle, bulking } \\
\text { attitude, lump appearance. }\end{array}$ \\
\hline MT7 & $\begin{array}{l}\text { Narrow grain size distribution, possible presence of } \\
\text { blocks, chip-shaped fragments, occurrence of fines } \\
\text { also relevant, abrasivity. } * \text { Technique suitable only } \\
\text { for low water flow rates. In wet conditions, } \\
\text { difficulties in handling operations. }\end{array}$ \\
\hline MT8 & $\begin{array}{l}\text { Irregular shaped fragments, wide grain size } \\
\text { distribution, petrography heterogeneity, *Muddy } \\
\text { consistency, low drainage capability. }\end{array}$ \\
\hline MT9 & $\begin{array}{l}\text { Similar to MT5, generally rounded shaped elements, } \\
\text { good drainage. *Granular behaviour }\end{array}$ \\
\hline MT10 & $\begin{array}{l}\text { Narrow grain size distribution closed around silt and } \\
\text { clay with presence of sand, homogeneous } \\
\text { mineralogy, plastic behaviour, or muddy due to } \\
\text { natural moisture. *Technique suitable only for low } \\
\text { water contents. }\end{array}$ \\
\hline MT11 & $\begin{array}{l}\text { Heterogeneous grain sizes, mineralogy and } \\
\text { consistency (from wet to flowing behaviour), } \\
\text { lubricated, possible adhesive behaviour, low } \\
\text { drainage capability under additive effects. Presence } \\
\text { of surfactants, polymers, traces of grease. }\end{array}$ \\
\hline MT12 & $\begin{array}{l}\text { Similar to MT9 but increased flowing behaviour, } \\
\text { higher water content, time-dependent drainage } \\
\text { capability. Presence of surfactants, polymers, filler } \\
\text { added, traces of grease, possibly bentonite. }\end{array}$ \\
\hline MT13 & $\begin{array}{l}\text { Similar to MT10, often muddy to sticky, presence of } \\
\text { surfactants and polymers, traces of grease, very low } \\
\text { drainage capability. }\end{array}$ \\
\hline MT14 & $\begin{array}{l}\text { Similar to MT1, presence of shotcrete, synthetic } \\
\text { lubricants, steel fibres, fibreglass, injection grout. }\end{array}$ \\
\hline MT15 & $\begin{array}{l}\text { Depending on actual cases MT2, MT4, MT8 } \\
\text { presence of shotcrete, synthetic lubricants, steel } \\
\text { fibres, fibreglass, injection grout. }\end{array}$ \\
\hline MT16 & $\begin{array}{l}\text { Depending on actual cases MT5, MT9, presence of } \\
\text { grouts, possibly fibreglass, shotcrete and fibres. }\end{array}$ \\
\hline MT17 & $\begin{array}{l}\text { Depending on actual cases MT6, MT10, presence of } \\
\text { grouts, possibly fibreglass, resin elements, } \\
\text { sometimes shotcrete. }\end{array}$ \\
\hline
\end{tabular}

Main characterisation tests are also suggested, ranking the relevance of each test versus the final destination of the materials. The methodology was applied to a number of case studies, proving its 
suitability in delivering appropriate guidance for the development of reuse strategies for waste geomaterials.

\section{Extension of the method to non- conventional materials}

\subsection{End-of-waste status}

The reuse of non-conventional materials, i.e. materials others than those having an economic value (gravel, sand, geosynthetics), has a great relevance as it is typically accompanied by savings in disposal costs as well as in the procurement of raw materials. Examples of such non-conventional materials are wooden chips, granulates, waste glass powder, out-of-shape residues from manufacturing processes or leftover from the triage of other waste after processes aimed at obtaining inert materials (so called 'end-of-waste').

'End-of-waste' status for waste stream is achieved when the waste material ceases to be considered an actual waste when specific conditions are met. 'End-ofwaste' status ensures a high level of environmental protection as well as environmental and economic benefits. Possible waste streams for which 'end-ofwaste' specifications and criteria should be developed are, among others, construction and demolition waste, metallurgical by-products, thermal treatment residues, scrap metals, exhaust tyres, waste textiles and paper, compost, and glass. In order to reach 'end-of-waste' status, the waste recovery operations do not need to be excessively onerous, often it is enough to check that the waste itself has clear and direct utilisation strategies for fulfilling the 'end-of-waste' criteria [14].

\subsection{Recycling issues for non-conventional materials}

Non-conventional waste materials share with geotechnical materials a number of features. The variability in composition, size distribution and shape of the elements of such materials can be assessed by adapting conventional geotechnical characterisation tests. The similarities between 'bulk' non-conventional waste materials and waste geomaterials refer to the geometric ratios, but the most important common feature is the different behaviour at small scale (laboratory) and at a large scale (worksite), which makes predictions on this latter based on evidences from the former broadly inaccurate. It is therefore required to investigate the material at 'element' level for assessing its intrinsic properties, as well as at 'bulk' level, for understanding the properties and behaviour of contact points with the neighbouring elements (interfaces).

Similarly to waste geomaterials, the properties of non-conventional waste streams are closely connected to the processes that led to their production and nature. Element sizes, grading distribution, physical, mechanical and chemical properties and their interaction with water are due to factors as: the initial material for manufacture (i.e. the 'geological conditions'), the industrial process that the material underwent (i.e. the 'excavation techniques'), the post-production treatment (i.e. the 'insitu treatments of spoils').

Geotechnical properties of these heterogeneous materials are today involving adaptation of classical approaches and instrumentation, thus leading to a specific branch in testing range and on site behaviour for strength and deformability.

The potential recycling options (i.e. the 'final destination of materials') have an impact on the required treatments. An "ambitious" purpose for the reuse of these materials could be as "engineered strata" in multilayer systems, such as backfilling, sub-base for paving, or drainage in civil or environmental landfilling works.

The assessment of environmental and chemical properties of the materials is of paramount importance, as well as the characterisation of leachates in terms of possible contaminations due to decomposition or biodegradation of material components.

Non-conventional materials can be originated from different streams: excavation or demolition waste from civil works; overburden and not productive geological layers from mining and extractive activities; environmental-related activities (cleaning, filtering etc.); industrial activities; quarrying production of ornamental stones. Regional or national boards usually provide technical regulations to properly follow these materials. Figures 1 to 5 show some examples.

The management of residues generated during mining operations, such as tailings and waste-rock, typically represent an undesired financial burden on operators. The mine site as well as the mineral processing plant are designed aiming at the extraction of as much marketable products as possible, and the residue and overall environmental management is then planned as a consequence of the applied process steps [15].

Pre-sorting and selective handling methods enable the separation of potentially valuable materials from the waste stream before sending the waste itself for treatment and/or disposal. These methods can also allow the separation of hazardous and non-inert waste streams from inert waste streams. In this latter case, the main requirement is the selective assessment of potentially acid generating versus non-acid generating extractive wastes [16].

Typical tests for the characterisation of nonconventional waste streams include the assessment of physical (grain size distribution, morphometry, loose and densified unit weight, and compaction parameters), mechanical (compressibility, elastic recovery in unloading, internal shear strength and shearing properties at interfaces with the geosynthetics, determination of the repose angle) and site-specific (determination of dimensional stability, resistance at different compaction levels by means of penetrometer testing, determination of real scale hydraulic permeability) properties.

Other specific tests can investigate the toughness properties, freezing response, water absorption and cohesion, fire resistance. 


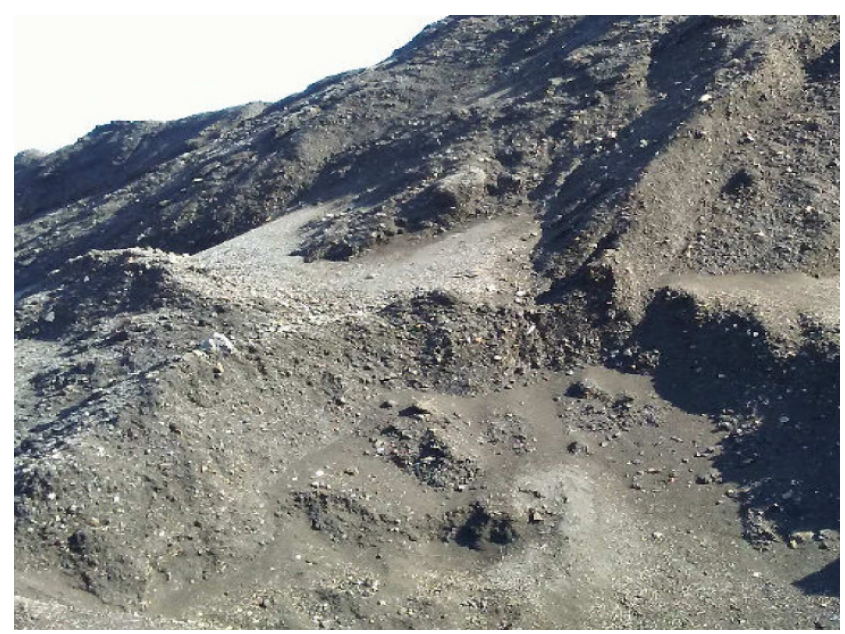

Fig. 1. Granular material arising from comminution and sieving of mix of soils, glass, gypsum, rockwool, glasswool (image at $10 \mathrm{~m}$ scale).

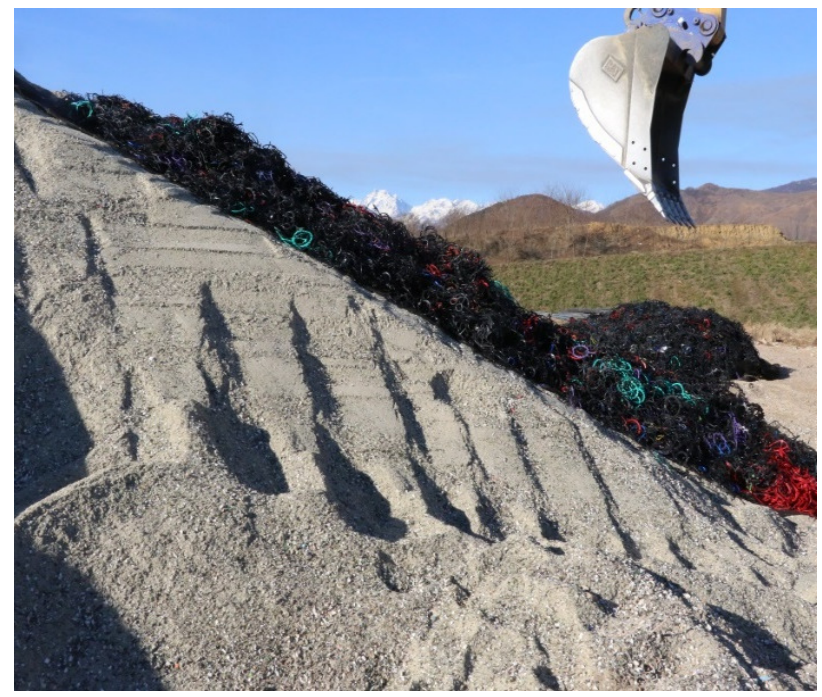

Fig. 2. Two types of non-conventional materials: the slope in the foreground is made of different fragmented and sieved glass; the bench in the background is made of polymeric cuttings from gasket production (credits Oggeri 2019).

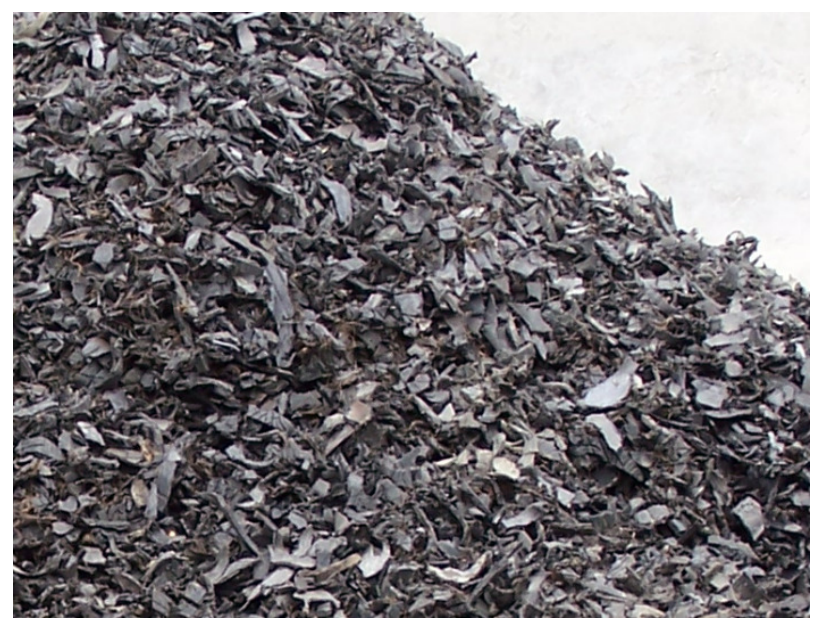

Fig. 3. Shredded exhausted tires (image at $1 \mathrm{~m}$ scale).

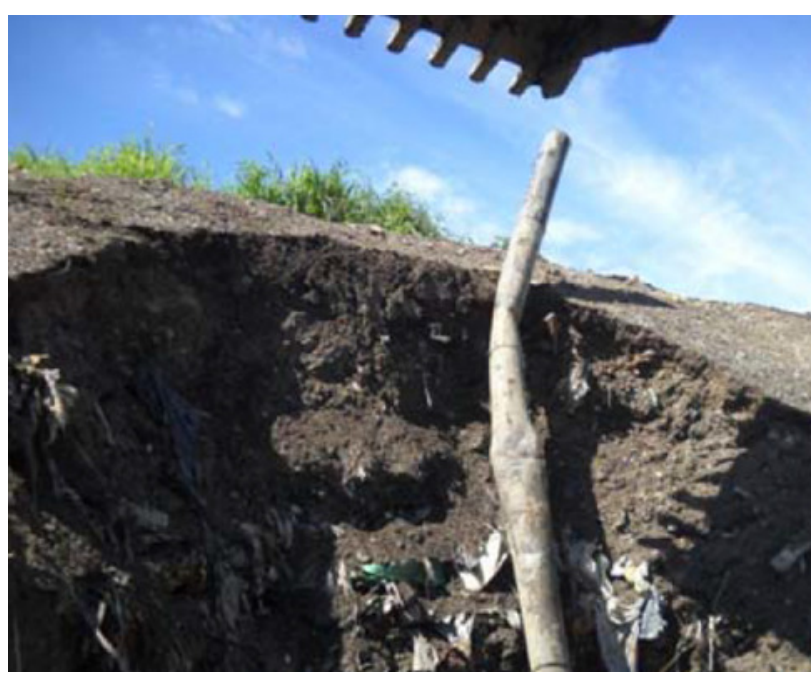

Fig. 4. Temporary covering of non hazardous waste dump with engineered material arising from mixed soils, glass, debris from clean water sedimentation (credits Oggeri 2014).

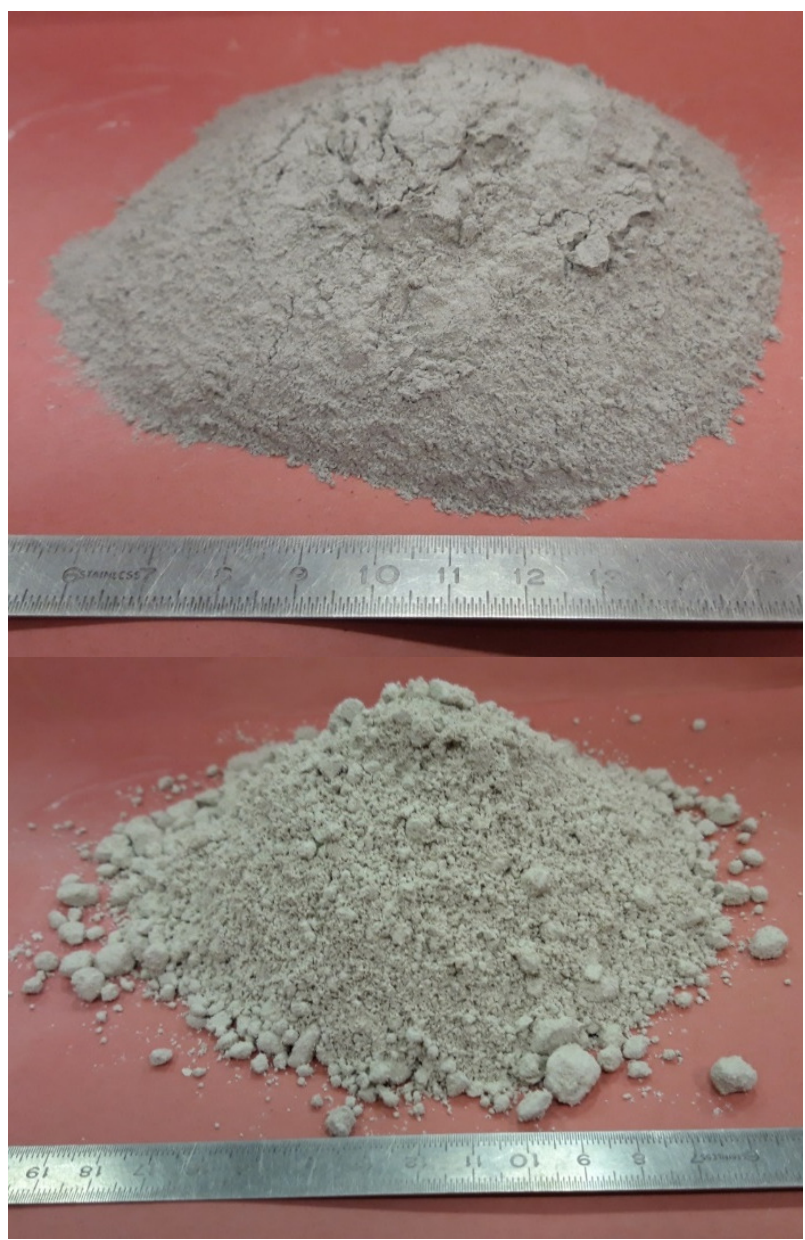

Fig. 5. Fine powder from quarrying/mining activities currently not recycled. (Top) from dry comminution process of olivine minerals. (Bottom) from wet comminution of quartz minerals (credits Oggeri 2019).

Sampling and specimen preparation have also a significant influence, as sometimes these materials are used in thin layers and this needs to be taken into account when assessing the investigated properties at laboratory level. Moreover, shape of fragments can 
request particular care for the preparation of the sample. Similarly, testing equipment could need special requirements, e.g. a long run for the characterisation of residual shear strength (up to $30 \mathrm{~cm}$ ). Interaction with ground water or rainwater is also to be taken into account for ensuring geometric stability of embankments and for ensuring the release of pollutants is avoided.

The legislation and technical prescriptions for these recovered materials are numerous and wide, both from the administrative point of view as well as tackling technical issues for reuse. Moreover, environmental and health and safety constraints have to be taken into account. There is a lack of harmonisation among countries as specific regulations can vary significantly.

Nowadays there are some examples of practical applications, and technical standards are under revision in order to be adapted to this new sector. Landfill structures, reclamation, filling, earth works, subgrade in paving, recycled masonry could be perspective interesting fields of application.

Among the potential options of recycling, some suggestions can cover the following [3]:

- the use as aggregates requires a complete removal of additives, as technical requirements adopt clean materials that will be mixed for concrete preparation; the aggregate is previously washed as it does not produce other leachates when in contact with the water of the concrete mixture. This context reflects the complex chemistry of cement reactions, where other substances can affect the short and long term behaviour as far as hydration and durability are concerned;

- the use as material for embankments involves compaction requirements, shear strength and bearing capacity (e.g. rockfall defence); these features can be influenced by the use of additives as they can modify the behaviour of the muck in terms of stickiness, plasticity, abrasiveness, consistency, water conductibility and friction parameters;

- in the case of land reclamation, mining reclamation [17] and filling the mechanical performances are less challenging, while chemical issues become more relevant in the view of avoiding the production of new leachate and diffusion of minor contaminants ;

- other uses, as in agriculture, civil reclamation, landfill capping should be studied case by case.

Finally, the technological and economic sustainability of these processes should be accompanied by a real commitment from all the involved stakeholders, from policymakers to industrial actors, in exploring and fostering these recycling options, otherwise it will remain a mere and marginal activity without real impact on economy, society and environment.

\section{Conclusions}

There is a strong request for a balance between the amount of waste or non-productive materials arising from civil or mining excavations (debris, burden, spoils, mud) and from industry (mud, sludge, cuttings, sands) versus the claim for their reuse, even if partial.
A huge field of interest is the possible reuse of muck and of overburden from quarries. The first step for successfully engage in significant recover of these materials is the availability of a robust classification system that enables to determine the proper technical and chemical path to address a convenient and suitable reuse.

In a similar way, efforts have been done to look for applications, even if marginal, of non-conventional materials, originated in different and unpredictable ways. The assessment of the behaviour of these materials is required, especially when these are used in specific applications, such as for the creation of drainage layers, for covering of dumps, for rehabilitation and reclamation of old or abandoned sites.

Sampling methods, testing equipment and procedures, as well as geotechnical and physical characterisation are the three main aspects that need a special care when investigating these materials, because their real scale properties (that is when working on site) and short- and long- term behaviour can show significant variations with respect to traditional raw material.

The process for improving the quality of these materials should be simple, inexpensive and requiring simple plants: crushing, sieving, desiccation, mixing, sorting, cleaning and chemical stabilisation (with binders) could be considered for maintaining the mentioned balance, both in terms of quantities as well as of cost savings.

\section{References}

1. P. V. Sáez and M. Osmani, A diagnosis of construction and demolition waste generation and recovery practice in the European Union, J. of Cleaner Production, 118400 (2019).

2. DEFRA, UK Statistics on Waste, Department for Environment, Food and Rural Affairs, UK, (2019).

3. C. Oggeri, T. M. Fenoglio and R. Vinai, Tunnel spoil classification and applicability of lime addition in weak formations for muck reuse, Tunnelling and Underground Space Technology 44, 97-107 (2014).

4. S. Ritter, H. Einstein and R. Galler, Planning the handling of tunnel excavation material - A process of decision making under uncertainty, Tunnelling and Underground Space Technology 33, 193-201 (2013).

5. J. Kwan and F. Jardine, Ground engineering spoil: Practices of disposal and reuse, Engineering geology 53 (2), 161-166 (1999).

6. A. B. Caracciolo, N. Ademollo, M. Cardoni, A. Di Giulio, P. Grenni, T. Pescatore, J. Rauseo and L. Patrolecco, Assessment of biodegradation of the anionic surfactant sodium lauryl ether sulphate used in two foaming agents for mechanized tunnelling excavation, Journal of hazardous materials, 365, 538-545 (2019). 
7. R. Galler, Tunnel excavation material - waste or valuable mineral resource? - European research results on resource efficient tunnelling, Proceedings of the WTC 2019 ITA-AITES World Tunnel Congress, Naples, (2019).

8. S. Magnusson, M. Johansson, S. Frosth and K. Lundberg, Coordinating soil and rock material in urban construction - Scenario analysis of material flows and greenhouse gas emissions, Journal of cleaner production, 118236 (2019).

9. A. G. Correia, M. Winter and A. Puppala, Coordinating soil and rock material in urban construction - Scenario analysis of material flows and greenhouse gas emissions, Transportation Geotechnics 7, 21-28 (2016).

10. S. Magnusson, K. Lundberg, B. Svedberg and S. Knutsson, Sustainable Management of Excavated Soil and Rock in Urban Areas - A Literature Review., Journal of Cleaner Production, 93, 18-25 (2015).

11. K. Kataguiri, M. E. G. Boscov, C. E. Teixeira and S. C. Angulo, Characterization flowchart for assessing the potential reuse of excavation soils in Sao Paulo city, Journal of Cleaner Production, 118215 (2019).

12. A. Rahimzadeh, W. Tang, W. Sher and P. Davis, Management of Excavated Material in Infrastructure Construction-A Critical Review of Literature, in International Conference on Architecture and Civil Engineering (Sydney, 2018).

13. C. Oggeri, T.M. Fenoglio and R. Vinai, Tunnelling muck classification: definition and application, Proceedings of the ITA- AITES World Tunnel Congress 2017, Bergen, Norway (2017).

14. European Commission, Directive 2008/98/EC 19 November 2008.

15. European Commission, Reference Document on Best Available Techniques for Management of Tailings and Waste-Rock in Mining Activities, January 2009.

16. European Commission, Best Available Techniques Reference Document for the Management of Waste from the Extractive Industries, in accordance with Directive 2006/21/EC. JRC, Draft document, June 2016.

17. C. Oggeri, T.M. Maria Fenoglio, A. Godio, R. Vinai, Overburden management in open pits: options and limits in large limestone quarries, International Journal of Mining Science and Technology, 29(2), pp. 217-228 (2019). 